\title{
Human Innate Lymphoid Cells: Their Functional and Cellular Interactions in Decidua
}

\author{
Paola Vacca $^{1 *}$, Chiara Vitale ${ }^{2,3}$, Enrico Munari ${ }^{4,5}$, Marco Antonio Cassatella ${ }^{6}$, Maria Cristina \\ Mingari $^{2,3,7}$ and Lorenzo Moretta ${ }^{1}$
}

\begin{abstract}
${ }^{1}$ Department of Immunology, IRCCS Bambino Gesù Children's Hospital, Rome, Italy, ${ }^{2}$ Department of Experimental Medicine (DIMES), University of Genoa, Genoa, Italy, ${ }^{3}$ UOC Immunology, IRCCS Ospedale Policlinico San Martino Genova, Genoa, Italy, ${ }^{4}$ Department of Pathology, Sacro Cuore Don Calabria Hospital, Negrar, Italy, ${ }^{5}$ Department of Pathology AOUI, University of Verona, Verona, Italy, ${ }^{6}$ Department of Medicine, Section of General Pathology, University of Verona, Verona, Italy, ${ }^{7}$ Center of Excellence for Biomedical Research (CEBR), University of Genoa, Genoa, Italy
\end{abstract}

\section{OPEN ACCESS}

Edited by:

Julia Szekeres-Bartho,

University of Pécs, Hungary

Reviewed by:

Nardhy Gomez-Lopez,

Wayne State University School of

Medicine, United States

Shomyseh Sanjabi,

University of California, San

Francisco, United States

*Correspondence:

Paola Vacca

paola.vacca@opbg.net

Specialty section:

This article was submitted to Immunological Tolerance and

Regulation,

a section of the journal

Frontiers in Immunology

Received: 27 June 2018

Accepted: 31 July 2018

Published: 14 August 2018

Citation:

Vacca P, Vitale $C$, Munari E, Cassatella MA, Mingari MC and

Moretta L (2018) Human Innate Lymphoid Cells: Their Functional and Cellular Interactions in Decidua.

Front. Immunol. 9:1897.

doi: 10.3389/fimmu.2018.01897
Innate lymphoid cells (ILC) are developmentally related cell subsets that play a major role in innate defenses against pathogens, in lymphoid organogenesis and in tissue remodeling. The best characterized ILC are natural killer (NK) cells. They are detectable in decidua in the early phases of pregnancy. During the first trimester, NK cells represent up to $50 \%$ of decidua lymphocytes. Differently from peripheral blood (PB) NK cells, decidual NK (dNK) cells are poorly cytolytic, and, instead of IFN $\gamma$, they release cytokines/chemokines that induce neo-angiogenesis, tissue remodeling, and placentation. dNK interact with resident myeloid cells and participate in the induction of regulatory $T$ cells that play a pivotal role in maintaining an efficient fetal-maternal tolerance. dNK cells may originate from CD34+ precursor cells present in situ and/or from immature NK cells already present in endometrial tissue and/or from PB NK cells migrated to decidua. In addition to NK cells, also ILC3 are present in human decidua during the first trimester. Decidual ILC3 include both natural cytotoxic receptor (NCR) ${ }^{+}$and $\mathrm{NCR}^{-}$cells, producing respectively IL-8/L-22/GM-CSF and TNF/IL-17. NCR+ILC3 have been shown to establish physical and functional interactions with neutrophils that, in turn, produce factors that are crucial for pregnancy induction/ maintenance and for promoting the early inflammatory phase, a fundamental process for a successful pregnancy. While NCR+ILC3 display a stable phenotype, most of NCR-ILC3 may acquire phenotypic and functional features of $\mathrm{NCR}^{+} I L C 3$. In conclusion, both NK cells and ILC3 are present in human decidua and may establish functional interactions with immune and myeloid cells playing an important role both in innate defenses and in tissue building/remodeling/placentation during the early pregnancy. It is conceivable that altered numbers or function of these cells may play a role in pregnancy failure.

Keywords: innate lymphoid cell, innate immunity, natural killer cells, human pregnancy, neutrophils, stromal cells, inflammation, tolerance

\section{INTRODUCTION}

The fetus can be considered as a semi-allograft to the maternal host; therefore, pregnancy should include mechanisms to prevent allograft rejection (1-3). During the early phases of pregnancy, an appropriate balance between inflammation and tolerance is critical for a successful pregnancy $(4,5)$. Indeed, pro-inflammatory cytokines have been shown to contribute to tissue building/remodeling 
and neo-angiogenesis, thus favoring embryo implantation (6-8). The inflammatory phase is followed by a regulatory phase characterized by an increase in regulatory $\mathrm{T}$ cells (Tregs) that prevent an excessive inflammation and avoid fetal immuno-mediated rejection (9). Thus, relevant interactions among cells involved in immune response may occur at the fetal-maternal interface and play a fundamental role for a successful pregnancy.

\section{GENERAL CHARACTERISTICS OF INNATE LYMPHOID CELLS (ILC) SUBSETS}

Innate lymphoid cells are immune effector cells involved in host defenses against pathogens and tumors, in lymphoid organogenesis and in secondary lymphoid organ remodeling after birth. ILCs are tissue-resident cells mainly found at the mucosal surfaces of intestine (10), lungs (11), decidua (12), and skin (13, 14). Thanks to their strategic location, ILC are among the first immune cells to respond to pathogens. Recently, on the basis of their cytokine profile and transcription factors (TF), ILC have been classified into two main groups: cytotoxic- and helper-ILC (15-18). Natural killer (NK) cells, representing cytotoxic-ILC, are the first innate lymphoid cell population described, featuring the capacity of killing virus-infected or tumor cells and to release pro-inflammatory cytokines and chemokines. Human NK cell function is regulated by an array of inhibitory receptors, such as the HLA-I-specific killer immunoglobulin-like receptors and CD94/NKG2A, and by activating receptors, including natural cytotoxicity receptors (NCR, i.e., NKp46, NKp30, and NKp44), NKG2D, DNAM-1, and CD16 $(19,20)$. The other ILC are represented by "helper"-ILC that are further classified into three main subsets (ILC1/ILC2/ILC3) (21). ILC1 mainly produce IFN $\gamma$ and provide defenses against intracellular bacteria and protozoa (22). In humans, two different subsets of ILC1 have been described in the intestine $(23,24)$. ILC2 mainly release type- 2 cytokines, such as IL-5, IL-13, and IL-4 and contribute to type-2 immune responses. Finally, ILC3 are a heterogeneous subset, their signature cytokines are represented by IL-17 and IL-22 (25). ILC3 were first identified in the fetus and were originally defined lymphoid tissue inducer (LTi) cells because of their key role in driving lymphoid organogenesis. In particular, during embryogenesis, LTi cells interact with stromal cells and induce upregulation of adhesion molecules thus promoting the development of lymph node structure. After birth, ILC3 are mainly located in secondary lymphoid organs (SLO), tonsils, decidua, and intestinal lamina propria where they contribute to host defenses against extracellular pathogens and are defined as LTi-like cells. In humans, LTi/ LTi-like cells are lineage (CD3/CD19/CD14/CD56)-negative and express CD127, CD117, retinoic acid receptor-related orphan receptor (ROR)- $\gamma \mathrm{t} \mathrm{TF}$, and secrete primarily IL-17 and TNF $\alpha$. A population of cells referred to as NCR + ILC3, sharing common features with both LTi-like cells and NK cells (type of cytokines production and NCR expression, respectively), has recently been identified in mucosal tissues and prevalently releases IL-22. ILC3-derived IL-22 acts on intestinal epithelial cells and induces not only production of antimicrobial peptides but also epithelial cell migration and wound healing. Moreover, ILC3 promote tissue repair and remodeling of SLO damaged by inflammatory processes. Conversely, ILC3 may also exert a pro-inflammatory role in intestinal inflammatory diseases.

All ILC subsets are developmentally related. Evidence in mice and humans indicates that NK cells and helper-ILC derive from a common ILC progenitor (CILP). As B and T lymphoid progenitors, the CILP derive from the common lymphoid progenitor. The acquisition of mature stages is dependent by different TF. Thus, NK cell differentiation involves Eomes, which regulates the expression of IFN $\gamma$ and of the cytolytic machinery, while terminal differentiation of helper-ILC is regulated by other TF. In particular, ILC1 requires Tbet, ILC2 GATA3, and ROR $\alpha$, and ILC3 ROR $\gamma$ t and AhR (26-29). Although, specific ILC3committed precursors have been defined, a precise identification of a common ILC precursor in humans is still lacking. Moreover, it is still only partially understood which signals from the microenvironment are driving their differentiation. The low numbers of ILC3 that can be generated in vitro has so far hampered studies aimed to answer these questions. Moreover, limitations in cell numbers may be an obstacle for clinical application of ILC. Thus, the development of protocols allowing the generation of suitable numbers of given subsets of ILC for their use in adoptive cell therapy is required.

Along this line, it has become more evident that the fate of ILC determination and their stability is not set in stone, but that there is some plasticity between different ILC subsets, depending on various signaling, including cytokines and exposure to different tissue-specific microenvironments. This would indicate that microenvironmental conditions might drive this plasticity from an ILC subset to another (29). Accordingly, it is conceivable that also putative differentiated ILC may display intermediate phenotypic/functional characteristics $(30,31)$.

\section{ILC IN HUMAN DECIDUA AND THEIR INTERACTIONS WITH DECIDUA MICROENVIRONMENT}

Innate immune cells are important components of the decidual microenvironment. In this tissue, the best characterized and most abundant ILCs are NK cells $(1,2,32)$. Remarkably, while the function of peripheral blood (PB) NK cells is to defend the host against infections and tumors, thanks to their cytolytic activity and production of cytokines, such as IFN- $\gamma$ and TNF, decidual NK (dNK) cells are characterized by a regulatory function (33). It has been shown that the NK cell function is greatly influenced by the microenvironment, including cytokines (34), chemokines, and cell-to-cell interactions. A paradigmatic example of how NK cell function may be regulated in tissues is provided by human dNK cells. They represent as much as $50-70 \%$ of decidual infiltrating lymphocytes during the first trimester of pregnancy, and are characterized by $\mathrm{CD} 56^{\text {bright }} \mathrm{CD} 16^{-} \mathrm{KIR}^{+} \mathrm{CD} 9^{+}$phenotype $(2,35)$. In spite of their high content of cytolytic granules, dNK cells are poorly cytotoxic and release very low amounts of IFN $\gamma$ as compared to PB-NK cells $(2,36-39)$. On the other hand, dNK cells release peculiar cytokines and chemokines, such as vascular endothelial growth factor (VEGF), stromal derived 
factor-1 (SDF-1 also identified as CXCL12), and IFN- $\gamma$-inducing protein 10 (IP10 also known as CXCL10), that mediate neoangiogenesis, tissue remodeling, and placentation (3). Similarly, to humans, also murine dNK cells are abundant during the early phases of pregnancy and display unique phenotypic and functional features (40-44). Several reports revealed that NK cells are present also in non-pregnant endometrial tissue and that their proportions may vary during the menstrual cycle. It has been shown that, besides NK cells, other ILC populations are present in human decidua during the early phases of pregnancy $(12,41)$ This finding supports the notion that ILC participate to defensive/ tissue building processes necessary for the maintenance/success of pregnancy $(45,46)$. Notably, decidual tissues contain different ROR $\gamma \mathrm{t}^{+}$ILC3 subsets displaying functional features similar to those previously described in other tissues. In particular, dILC3 not only express IL-22, but are also the main IL- 8 producers, a functional activity previously assigned to dNK cells. Moreover, dILC3 have been shown to induce the expression of adhesion molecules (a functional activity referred to LTi-like cells) on decidual stromal cells (DSC), thus suggesting that, also dILC3, may play a role in tissue building/remodeling during the early phases of pregnancy.

\section{ORIGIN OF DECIDUAL ILC}

Given the relevant role of $\mathrm{dNK}$ cells in the maintenance of pregnancy, an important issue is to clarify their origin. NK cells are known to originate from $\mathrm{CD} 34^{+}$hematopoietic stem cell, as revealed by a number of studies both in vitro and in vivo. These precursors are present mainly in the bone marrow, and also in PB and cord blood. Although, it is possible that $\mathrm{dNK}$ cells may derive from PB-NK cells migrated in decidua, where they acquire unique functional features upon exposure to the decidual microenvironment $(47,48)$, they may also derive from $\mathrm{CD} 34^{+}$precursors detectable in decidua. In this context, previous studies described the presence of $\mathrm{CD}^{2} 4^{+} \mathrm{VEGFR}^{-}$precursors in decidual tissues and of immature NK cells in endometrial tissue (47-51). Both cell populations could undergo differentiation into $\mathrm{dNK}$ cells during pregnancy. Remarkably, dCD $34^{+}$cells are committed toward the NK cell lineage as revealed by experiments showing that they undergo rapid in vitro differentiation toward mature NK cells both in the presence and in the absence of cytokines, provided they are co-cultured with DSC $(3,52)$.

The issue of the developmental relationship between different ILC is a matter of debate. In particular, the relationship between NK cells and ILC3 is unclear in humans, because the phenotypic features of immature NK cells and ILC3 are partially overlapping. It was originally proposed that $\mathrm{NCR}^{+} \mathrm{ILC} 3$ represent an immature stage of NK cell development $(53,54)$. However, decidual ILC3, despite their extensive proliferative capacity, maintain their phenotypic and functional characteristic, while only a minor fraction could differentiate toward CD $94^{+} \mathrm{NK}$ cells even in the presence of IL-15. Similarly, to $\mathrm{NCR}^{+}$ILC3, also LTi-like cells virtually failed to generate NK cells. Thus, it is conceivable that the majority of NK cells present in decidual tissue may derive from PB-NK cells migrated to decidua, as well as from $\mathrm{CD} 34^{+}$cell precursors detectable in situ. On the other hand, our recent studies support the notion that a developmental relationship exists between the two ILC3 subsets present in decidua. Indeed, $\mathrm{NCR}^{+}$ILC3 (expressing CD56) could be derived from LTi-like CD56 ${ }^{-}$cells. In these in vitro experiments, only a small percentage of LTi-like cells retained their phenotypic characteristics $\left(\mathrm{Lin}^{-} \mathrm{CD} 56^{-} \mathrm{CD} 117^{+} \mathrm{CD} 127^{+}\right.$), while they acquired the $\mathrm{Lin}^{-} \mathrm{CD} 56^{+} \mathrm{CD} 117^{+} \mathrm{CD} 127^{+} \mathrm{CD} 94^{-} \mathrm{NCR}^{+}$ phenotype (12). It cannot be excluded that, similarly to NK cells, also ILC3 may derive from precursors present in decidua. Indeed, ILC3 are not present in PB, implying that they should develop in situ from a precursor. Interestingly, $\mathrm{dCD} 34^{+}$precursors are characterized by the expression of ID2 transcription factor, which is required for ILC development, suggesting that $\mathrm{dCD} 34$ cells may give rise not only to $\mathrm{dNK}$ cells but also to $\mathrm{NCR}^{+} \mathrm{ILC}_{3}$ and LTi-like cells (12).

Although NK cells belong to the innate immune system, different reports suggested that they may display adaptive-like properties. These adaptive features include clonal expansion and the generation of long-lived memory cells (55-58). In humans, "trained/memory" NK cells are characterized by the expression of HLA-class I-specific activating receptor NKG2C (59). The $\mathrm{NKG}_{2} \mathrm{C}^{+} \mathrm{NK}$ cell subset undergo great expansion following human cytomegalovirus infection $(55,60)$. Several observations indicate that a major risk of a deficient placentation occurs in women that undergo first pregnancy $(61,62)$. These data suggest that, after the first pregnancy, the uterine microenvironment may acquire the ability to better sustain the early phase of placentation, including the inflammatory process. In this context, it has been shown recently that the $\mathrm{dNK}$ cell repertoire significantly differs in primigravidae as compared to multigravidae. Mulitgravid women display higher percentages of $\mathrm{dNK}$ cells expressing NKG2C and LILRB1, which also produce higher amounts of IFN- $\gamma$ and VEGF as compared to dNK cells detectable in primigravid women. Precursors of these cells are present in the uterus between pregnancies and may become activated by the uterine microenvironment once a new pregnancy occurs. These cells could represent "trained" NK cells that would improve endometrial vascularization, angiogenesis, and maintenance of decidua through a more prompt and abundant secretion of functional VEGF and IFN- $\gamma(63)$.

\section{INVOLVEMENT OF ILC IN THE INFLAMMATORY AND TOLEROGENIC PHASES OF PREGNANCY}

A successful pregnancy requires an early inflammatory phase that is necessary for successful implantation, while, subsequently, a regulatory/immunosuppressive phase should follow to prevent fetal rejection $(5,8,64)$. Several studies highlighted the role of innate and adaptive immune cells in promoting either an inflammatory or an immunosuppressive environment. It is conceivable that functional activities thought to be exclusive of adaptive immunity, may actually be mediated also by ILC (65). Thus, not only uterine Th17 but also dILC releasing pro-angiogenetic factors are likely to play a role in the neo-angiogenesis and antimicrobial defenses during pregnancy. 


\section{The Inflammatory Phase}

Different studies revealed the presence of neutrophils $(\mathrm{N})$ with pro-angiogenetic capability in human decidua during the first and the second trimesters of pregnancy $(66,67)$. In particular, during the first trimester, $\mathrm{N}$ present in human decidual tissues are characterized by an "activated" phenotype, production of fibro/ angiogenic factors and a prolonged survival. Previous studies reported that $\mathrm{NCR}^{+}$ILC3 could mediate neutrophil activation in spleen via GM-CSF (68). It has been shown that dILC3 could functionally interact with $\mathrm{N}$ in decidual tissues (Figure 1). In particular, it is conceivable that $\mathrm{dN}$ recruitment to decidua, their activation, and expression of peculiar immunoregulatory factors (HB-EGF and IL1ra) may be related to interaction with dILC3 $(69,70)$. Indeed, thanks to their ability to release IL8 and GM-CSF, dILC3 could promote neutrophil recruitment and activation, respectively. These observations support the notion that both ILC3 and N may play an important role in early inflammatory phase and, subsequently, in the induction of tolerance.

Recent studies revealed that also cytokines released by NK cells might induce neutrophil activation, expression of activation markers, and production of cytokines and angiogenic factors (71-73). In addition, under suitable experimental conditions, NK cells have been shown to induce neutrophil apoptosis (74). Reciprocally, N may inhibit NK cell proliferation, cytolytic activity, cytokine production, and survival via contact-dependent or -independent mechanisms (73). In agreement with the concept of $\mathrm{NK} / \mathrm{N}$ interactions in decidua, it has been observed that $\mathrm{dN}$ localize in close proximity of $\mathrm{CD}^{+} 6^{+}$cells, suggesting a potential crosstalk with $\mathrm{dNK}$ cells. Thus, it is possible to speculate that also decidual $\mathrm{N}$ by interacting with dILC3 and/or dNK cells may contribute to the regulation of innate/adaptive immune responses occurring during pregnancy, by the release of soluble factors, or cell-to-cell contacts (67). These data shed new light on the cellular and molecular mechanisms involved in the initiation of an inflammatory response in the decidua.

\section{The Tolerogenic Phase}

Since fetus is a semi-allograft, successful pregnancy should also include mechanisms capable of preventing allograft rejection. Indeed, while effective immune responses must be maintained in order to protect the mother from harmful pathogens, immune reaction against fetal antigens should also be avoided. dNK cells express normal levels of HLA-class I-specific inhibitory receptors. Notably, certain HLA-class I molecules are expressed by trophoblast and are involved in the regulation of trophoblast growth, differentiation, and invasion (75). The fact that dNK cells are unable to kill different target cells has been tentatively explained with the poor ability to form appropriate immunological synapses and/ or the expression of the inhibitory form of 2B4 co-receptor (39, 76). In addition, the fact that dNK cells do not kill trophoblastic

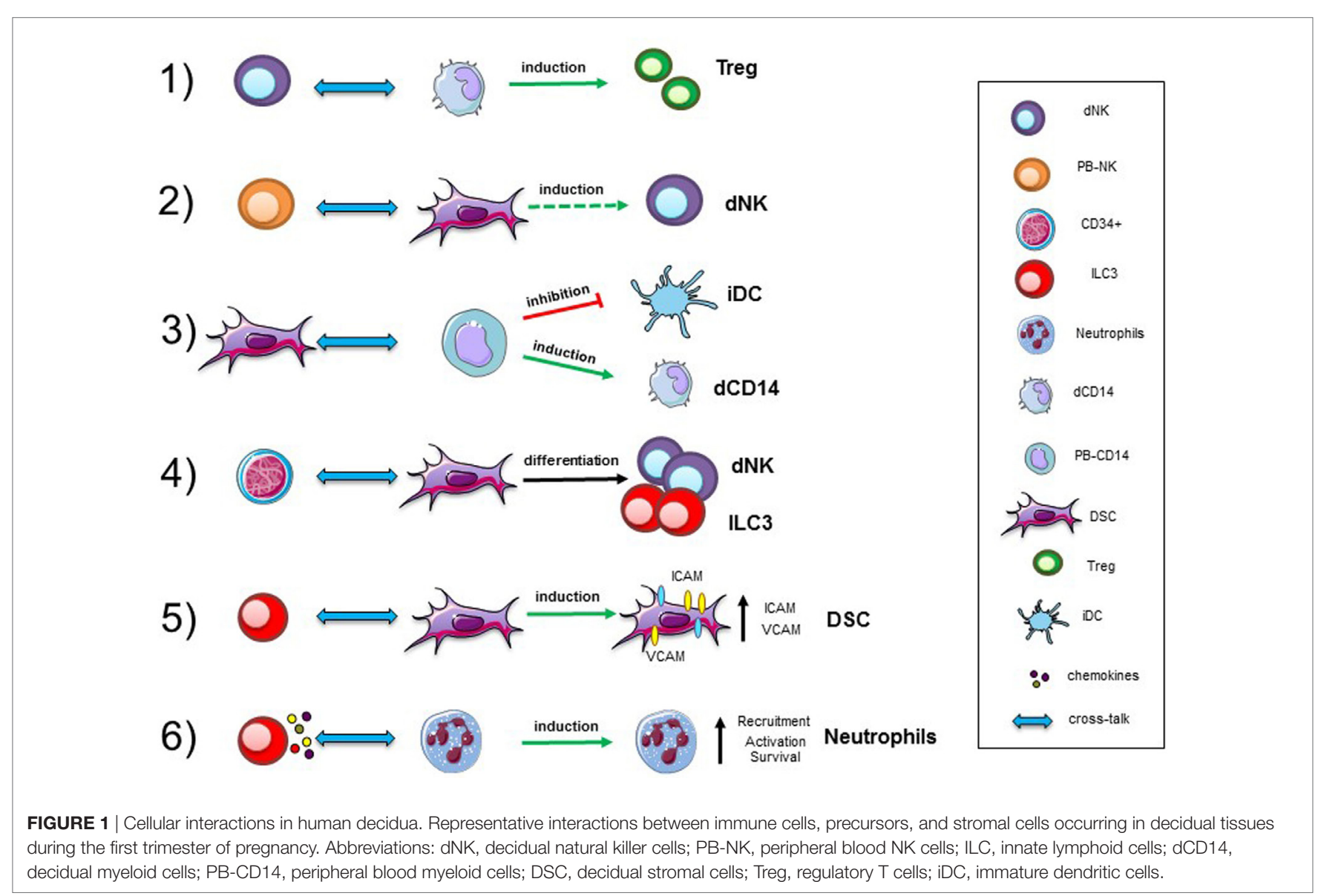


cells has also been explained with the expression of inhibitory NK receptors, such as CD94/NKG2A specific for HLA-E, recognizing HLA-G KIR2DL4 and KIR2DL1/2/3 specific for HLA-C, i.e., the HLA-class I molecules expressed by human trophoblast. Therefore, both the poor ability to kill of dNK cells and a number of fail-safe mechanism may be responsible for the inability of dNK cells to kill the invading trophoblast (7). Notably, also Tregs have been detected during early pregnancy and are thought to exert an important protective role when the maternal immune cells come into contact with fetal antigens expressed by invading trophoblast cells. Accordingly, studies in humans revealed the presence of Tregs in the PB during the early phases of normal pregnancy, while a low Treg numbers have been reported in cases of recurrent pregnancy loss (77). In this context, it should be stressed that different Treg subpopulations occur, including naturally occurring Tregs, which derive from the thymus, and adaptive Tregs, which develop in the periphery, The development of Tregs requires the transcription factor Forkhead box P3 which currently represents their most specific marker. The secretion of inhibitory cytokines and contact-dependent inhibition are two identified mechanisms of Treg-mediated suppression. Tregs may contribute to prevent autoimmune diseases and play a role in transplantation tolerance. Previous studies indicated that the increase of Treg in decidual tissue may be due either to the local expansion or to their selective recruitment at the maternal-fetal interface $(9,78)$.

Another remarkable cell population present in the decidua is represented by $\mathrm{CD} 14^{+}$cells, generally described as decidual myeloid cells (monocytes/macrophages) that did not express CD1a, a dendritic cell (DC) marker (79, 80). Histochemical analysis revealed that they may be in close association with dNK cells, and be involved in functional crosstalks with NK cells. In vitro experiments revealed that the interaction between $\mathrm{dNK}$ and $\mathrm{dCD} 14^{+}$cells results in the production of IFN- $\gamma$ which, in turn, induces indoleamine 2,3-dioxygenase (IDO) expression in $\mathrm{dCD} 14^{+}$cells. Such "conditioned" dCD $14^{+}$cells acquire the ability to induce Treg by a mechanism that involves TGF- $\beta$ production. Our perception of the role of $\mathrm{dNK}$ cells has thus evolved indeed, not only they do not attack trophoblastic cells but also they can play a major role in immune regulation, by promoting the development of Tregs upon functional interaction with $\mathrm{dCD} 14^{+}$cells (81) (Figure 1).

Decidual stromal cells represent other important component of decidual tissue. Indeed, decidual leukocytes are deeply influenced by these cells. On the other hand, also immune cells may modulate DSC function (82). Experimental evidences revealed that DSC, present in the early and late phases of pregnancy, may contribute to the induction of an anti-inflammatory and tolerogenic microenvironment crucial for the establishment/ maintenance of successful pregnancy. In this context, DSC have been shown to induce downregulation of major activating $\mathrm{NK}$ receptors and to inhibit NK cell proliferation, cytotoxicity, and IFN- $\gamma$ production. These inhibitory activities are related to the production of PGE2 and to the expression of IDO, resulting in kynurenine production. DSC display another important functional capability related to their ability to promote $\mathrm{CD} 34^{+}$cell differentiation. In this context, it has been described that endometrium and decidua contain $\mathrm{CD} 34^{+}$cell precursors $\left(\mathrm{dCD} 34^{+}\right)$ capable of differentiating in vitro into NK cells. Interestingly, even in the absence of exogenous cytokines, $\mathrm{dCD} 34^{+}$could give rise to dNK cells when co-cultured with DSC. Other leukocyte functional capabilities may be affected as a result of crosstalk with DSC (Figure 1). Thus, DSC, through IDO and PGE2, may affect the differentiation of PB-CD14 ${ }^{+}$cells toward DCs (82). Moreover, previous studies showed that placenta-derived stromal cells can mediate $\mathrm{T}$ cell suppression and induce Treg expansion through a mechanism involving IDO, PGE2, and PD-L1 (83).

Interaction among different cell types may imply a bidirectional crosstalk. Accordingly, also immune cells may influence DSC properties. For example, decidual ILC3 (in particular LTi-like cells) can induce upregulation of ICAM1 and VCAM1 on DSC. This effect is one of the starting events necessary for the development of secondary and tertiary lymphoid organs. In decidua, this effect could be involved in tissue remodeling, placentation, and leukocyte recruitment. Moreover, engagement of RANK has been shown to promote production of CCL2, which, in turn, favors DSC survival and proliferation (84). Moreover, since decidual ILC3 express RANKL it would be of interest to explore whether they can interact with DSC via RANKL/RANKmediated mechanisms.

\section{CONCLUSION}

As outlined in this contribution, during the first trimester of pregnancy, different cellular players deeply involved in the balance between inflammation and tolerance are present in decidual. In particular, decidual ILC, including NK cells, ILC3 and ILC1, upon interaction with stromal cells, neutrophils, myelomonocytic cells, and T lymphocytes may play a key role in the induction and maintenance of pregnancy. Notably, decidual ILC can originate from $\mathrm{CD}_{3} 4^{+}$precursors or immature lymphoid cells present in situ. In view of the role of ILC in pregnancy, it is possible to speculate that defects in ILC generation or functional interactions in decidual tissues may be a possible cause of fetal losses. While a better knowledge on these cells is clearly required before planning any future clinical application, these concepts open new scenarios of investigation both in innate immunity and in reproductive immunology.

\section{AUTHOR CONTRIBUTIONS}

All authors discussed together the general outline of the article. PV, $\mathrm{CV}$, and LM wrote the first draft that was subsequently reviewed by MAC, EM, and MCM. Thereafter, all authors contributed to the elaboration of the final version of the manuscript.

\section{FUNDING}

Supported by grants awarded by Associazione Italiana Ricerca per la Ricerca sul Cancro (AIRC) - Special Project " $5 \times 1000$ Molecular Clinical Oncology Extension Program” no. 9962 (LM) and " $5 \times 1000$ Immunity in Cancer Spreading and Metastasis (ISM) no. 21147 (LM); AIRC IG 2017 Id. 19920 (LM), AIRC 2014 Id. 15283 (LM), Ministero della Salute RF-2013, GR-201302356568 (PV). 


\section{REFERENCES}

1. Erlebacher A. Immunology of the maternal-fetal interface. Annu Rev Immunol (2013) 31:387-411. doi:10.1146/annurev-immunol-032712-100003

2. Moffett-King A. Natural killer cells and pregnancy. Nat Rev Immunol (2002) 2(9):656-63. doi:10.1038/nri967

3. Vacca P, Moretta L, Moretta A, Mingari MC. Origin, phenotype and function of human natural killer cells in pregnancy. Trends Immunol (2011) 32(11):517-23. doi:10.1016/j.it.2011.06.013

4. Mortha A, Chudnovskiy A, Hashimoto D, Bogunovic M, Spencer SP, Belkaid Y, et al. Microbiota-dependent crosstalk between macrophages and ILC3 promotes intestinal homeostasis. Science (2014) 343(6178):1249288. doi:10.1126/ science. 1249288

5. Saito S, Nakashima A, Shima T, Ito M. Th1/Th2/Th17 and regulatory T-cell paradigm in pregnancy. Am J Reprod Immunol (2010) 63(6):601-10. doi:10.1111/j.1600-0897.2010.00852.x

6. Hanna J, Goldman-Wohl D, Hamani Y, Avraham I, Greenfield C, NatansonYaron S, et al. Decidual NK cells regulate key developmental processes at the human fetal-maternal interface. Nat Med (2006) 12(9):1065-74. doi:10.1038/ nm1452

7. Vacca P, Cantoni C, Prato C, Fulcheri E, Moretta A, Moretta L, et al. Regulatory role of NKp44, NKp46, DNAM-1 and NKG2D receptors in the interaction between NK cells and trophoblast cells. Evidence for divergent functional profiles of decidual versus peripheral NK cells. Int Immunol (2008) 20(11):1395-405. doi:10.1093/intimm/dxn105

8. Mor G, Cardenas I, Abrahams V, Guller S. Inflammation and pregnancy: the role of the immune system at the implantation site. Ann N Y Acad Sci (2011) 1221:80-7. doi:10.1111/j.1749-6632.2010.05938.x

9. Aluvihare VR, Kallikourdis M, Betz AG. Regulatory T cells mediate maternal tolerance to the fetus. Nat Immunol (2004) 5(3):266-71. doi:10.1038/ ni1037

10. Cherrier M, Ohnmacht C, Cording S, Eberl G. Development and function of intestinal innate lymphoid cells. Curr Opin Immunol (2012) 24(3):277-83. doi:10.1016/j.coi.2012.03.011

11. Monticelli LA, Sonnenberg GF, Abt MC, Alenghat T, Ziegler CG, Doering TA, et al. Innate lymphoid cells promote lung-tissue homeostasis after infection with influenza virus. Nat Immunol (2011) 12(11):1045-54. doi:10.1031/ ni. 2131

12. Vacca P, Montaldo E, Croxatto D, Loiacono F, Canegallo F, Venturini PL, et al. Identification of diverse innate lymphoid cells in human decidua. Mucosal Immunol (2015) 8(2):254-64. doi:10.1038/mi.2014.63

13. Klose CS, Artis D. Innate lymphoid cells as regulators of immunity, inflammation and tissue homeostasis. Nat Immunol (2016) 17(7):765-74. doi:10.1038/ ni.3489

14. Villanova F, Flutter B, Tosi I, Grys K, Sreeneebus H, Perera GK, et al. Characterization of innate lymphoid cells in human skin and blood demonstrates increase of NKp44+ ILC3 in psoriasis. J Invest Dermatol (2014) 134(4):984-91. doi:10.1038/jid.2013.477

15. Diefenbach A, Colonna M, Romagnani C. The ILC world revisited. Immunity (2017) 46(3):327-32. doi:10.1016/j.immuni.2017.03.008

16. Colonna M. Innate lymphoid cells: diversity, plasticity, and unique functions in immunity. Immunity (2018) 48(6):1104-17. doi:10.1016/j. immuni.2018.05.013

17. Montaldo E, Vacca P, Moretta L, Mingari MC. Development of human natural killer cells and other innate lymphoid cells. Semin Immunol (2014) 26(2):107-13. doi:10.1016/j.smim.2014.01.006

18. Vacca P, Montaldo E, Croxatto D, Moretta F, Bertaina A, Vitale C, et al. NK cells and other innate lymphoid cells in hematopoietic stem cell transplantation. Front Immunol (2016) 7:188. doi:10.3389/fimmu.2016.00188

19. Moretta A, Bottino C, Vitale M, Pende D, Biassoni R, Mingari MC, et al. Receptors for HLA class-I molecules in human natural killer cells. Annu Rev Immunol (1996) 14:619-48. doi:10.1146/annurev.immunol.14.1.619

20. Moretta A, Bottino C, Vitale M, Pende D, Cantoni C, Mingari MC, et al. Activating receptors and coreceptors involved in human natural killer cell-mediated cytolysis. Annu Rev Immunol (2001) 19:197-223. doi:10.1146/ annurev.immunol.19.1.197

21. Eberl G, Di Santo JP, Vivier E. The brave new world of innate lymphoid cells. Nat Immunol (2014) 16(1):1-5. doi:10.1038/ni.3059
22. McKenzie AN, Spits H, Eberl G. Innate lymphoid cells in inflammation and immunity. Immunity (2014) 41(3):366-74. doi:10.1016/j.immuni.2014. 09.006

23. Bernink JH, Peters CP, Munneke M, te Velde AA, Meijer SL, Weijer K, et al. Human type 1 innate lymphoid cells accumulate in inflamed mucosal tissues. Nat Immunol (2013) 14(3):221-9. doi:10.1038/ni.2534

24. Fuchs A, Vermi W, Lee JS, Lonardi S, Gilfillan S, Newberry RD, et al. Intraepithelial type 1 innate lymphoid cells are a unique subset of IL-12- and IL-15-responsive IFN-gamma-producing cells. Immunity (2013) 38(4):76981. doi:10.1016/j.immuni.2013.02.010

25. Diefenbach A, Colonna M, Koyasu S. Development, differentiation, and diversity of innate lymphoid cells. Immunity (2014) 41(3):354-65. doi:10.1016/j. immuni.2014.09.005

26. Lee JS, Cella M, McDonald KG, Garlanda C, Kennedy GD, Nukaya M, et al. AHR drives the development of gut ILC22 cells and postnatal lymphoid tissues via pathways dependent on and independent of Notch. Nat Immunol (2011) 13(2):144-51. doi:10.1038/ni.2187

27. Montaldo E, Juelke K, Romagnani C. Group 3 innate lymphoid cells (ILC3s): origin, differentiation, and plasticity in humans and mice. Eur J Immunol (2015) 45(8):2171-82. doi:10.1002/eji.201545598

28. Montaldo E, Teixeira-Alves LG, Glatzer T, Durek P, Stervbo U, Hamann W, et al. Human RORgammat(+)CD34(+) cells are lineage-specified progenitors of group 3 RORgammat(+) innate lymphoid cells. Immunity (2014) 41(6):988-1000. doi:10.1016/j.immuni.2014.11.010

29. Lim AI, Verrier T, Vosshenrich CA, Di Santo JP. Developmental options and functional plasticity of innate lymphoid cells. Curr Opin Immunol (2017) 44:61-8. doi:10.1016/j.coi.2017.03.010

30. Cella M, Otero K, Colonna M. Expansion of human NK-22 cells with IL-7, IL-2, and IL-1beta reveals intrinsic functional plasticity. Proc Natl Acad Sci U S A (2010) 107(24):10961-6. doi:10.1073/pnas.1005641107

31. Spits H, Cupedo T. Innate lymphoid cells: emerging insights in development, lineage relationships, and function. Annu Rev Immunol (2012) 30:647-75. doi:10.1146/annurev-immunol-020711-075053

32. Vacca P, Mingari MC, Moretta L. Natural killer cells in human pregnancy. J Reprod Immunol (2013) 97(1):14-9. doi:10.1016/j.jri.2012.10.008

33. Le Bouteiller P, Tabiasco J. Killers become builders during pregnancy. Nat Med (2006) 12(9):991-2. doi:10.1038/nm0906-991

34. Marcenaro E, Della Chiesa M, Bellora F, Parolini S, Millo R, Moretta L, et al. IL-12 or IL-4 prime human NK cells to mediate functionally divergent interactions with dendritic cells or tumors. J Immunol (2005) 174(7):3992-8. doi:10.4049/jimmunol.174.7.3992

35. Moffett-King A, Entrican G, Ellis S, Hutchinson J, Bainbridge D. Natural killer cells and reproduction. Trends Immunol (2002) 23(7):332-3. doi:10.1016/ S1471-4906(02)02261-5

36. Verma S, King A, Loke YW. Expression of killer cell inhibitory receptors on human uterine natural killer cells. Eur J Immunol (1997) 27(4):979-83. doi:10.1002/eji.1830270426

37. Geiselhart A, Dietl J, Marzusch K, Ruck P, Ruck M, Horny HP, et al. Comparative analysis of the immunophenotypes of decidual and peripheral blood large granular lymphocytes and T cells during early human pregnancy. Am J Reprod Immunol (1995) 33(4):315-22. doi:10.1111/j.1600-0897.1995. tb00900.x

38. Sedlmayr P, Schallhammer L, Hammer A, Wilders-Truschnig M, Wintersteiger R, Dohr G. Differential phenotypic properties of human peripheral blood CD56dim+ and CD56bright+ natural killer cell subpopulations. Int Arch Allergy Immunol (1996) 110(4):308-13. doi:10.1159/ 000237321

39. Vacca P, Pietra G, Falco M, Romeo E, Bottino C, Bellora F, et al. Analysis of natural killer cells isolated from human decidua: Evidence that 2B4 (CD244) functions as an inhibitory receptor and blocks NK-cell function. Blood (2006) 108(13):4078-85. doi:10.1182/blood-2006-04-017343

40. Chiossone L, Vacca P, Orecchia P, Croxatto D, Damonte P, Astigiano S, et al. In vivo generation of decidual natural killer cells from resident hematopoietic progenitors. Haematologica (2014) 99(3):448-57. doi:10.3324/ haematol.2013.091421

41. Montaldo E, Vacca P, Chiossone L, Croxatto D, Loiacono F, Martini S, et al. Unique eomes(+) NK cell subsets are present in uterus and decidua during early pregnancy. Front Immunol (2015) 6:646. doi:10.3389/fimmu.2015.00646 
42. Gaynor LM, Colucci F. Uterine natural killer cells: functional distinctions and influence on pregnancy in humans and mice. Front Immunol (2017) 8:467. doi:10.3389/fimmu.2017.00467

43. Doisne JM, Balmas E, Boulenouar S, Gaynor LM, Kieckbusch J, Gardner L, et al. Composition, development, and function of uterine innate lymphoid cells. J Immunol (2015) 195(8):3937-45. doi:10.4049/jimmunol.1500689

44. Boulenouar S, Doisne JM, Sferruzzi-Perri A, Gaynor LM, Kieckbusch J, Balmas E, et al. The residual innate lymphoid cells in NFIL3-deficient mice support suboptimal maternal adaptations to pregnancy. Front Immunol (2016) 7:43. doi:10.3389/fimmu.2016.00043

45. Fu B, Zhou Y, Ni X, Tong X, Xu X, Dong Z, et al. Natural killer cells promote fetal development through the secretion of growth-promoting factors. Immunity (2017) 47(6):1100-13e6. doi:10.1016/j.immuni.2017.11.018

46. Xu Y, Romero R, Miller D, Silva P, Panaitescu B, Theis KR, et al. Innate lymphoid cells at the human maternal-fetal interface in spontaneous preterm labor. Am J Reprod Immunol (2018) 79(6):e12820. doi:10.1111/aji.12820

47. Carlino C, Stabile H, Morrone S, Bulla R, Soriani A, Agostinis C, et al. Recruitment of circulating NK cells through decidual tissues: a possible mechanism controlling NK cell accumulation in the uterus during early pregnancy. Blood (2008) 111(6):3108-15. doi:10.1182/blood-2007-08-105965

48. Santoni A, Carlino C, Stabile H, Gismondi A. Mechanisms underlying recruitment and accumulation of decidual NK cells in uterus during pregnancy. Am J Reprod Immunol (2008) 59(5):417-24. doi:10.1111/j.1600-0897.2008.00598.x

49. Male V, Hughes T, McClory S, Colucci F, Caligiuri MA, Moffett A. Immature NK cells, capable of producing IL-22, are present in human uterine mucosa. J Immunol (2010) 185(7):3913-8. doi:10.4049/jimmunol.1001637

50. Vacca P, Vitale C, Montaldo E, Conte R, Cantoni C, Fulcheri E, et al. CD34+ hematopoietic precursors are present in human decidua and differentiate into natural killer cells upon interaction with stromal cells. Proc Natl Acad Sci US A (2011) 108(6):2402-7. doi:10.1073/pnas.1016257108

51. Keskin DB, Allan DS, Rybalov B, Andzelm MM, Stern JN, Kopcow HD, et al. TGFbeta promotes conversion of CD16+ peripheral blood NK cells into CD16- NK cells with similarities to decidual NK cells. Proc Natl Acad Sci U S A (2007) 104(9):3378-83. doi:10.1073/pnas.0611098104

52. Croxatto D, Vacca P, Canegallo F, Conte R, Venturini PL, Moretta L, et al. Stromal cells from human decidua exert a strong inhibitory effect on NK cell function and dendritic cell differentiation. PLoS One (2014) 9(2):e89006. doi:10.1371/journal.pone.0089006

53. Ahn YO, Blazar BR, Miller JS, Verneris MR. Lineage relationships of human interleukin-22-producing CD56+ RORgammat+ innate lymphoid cells and conventional natural killer cells. Blood (2013) 121(12):2234-43. doi:10.1182/ blood-2012-07-440099

54. Montaldo E, Vitale C, Cottalasso F, Conte R, Glatzer T, Ambrosini P, et al. Human NK cells at early stages of differentiation produce CXCL8 and express CD161 molecule that functions as an activating receptor. Blood (2012) 119(17):3987-96. doi:10.1182/blood-2011-09-379693

55. Guma M, Angulo A, Vilches C, Gomez-Lozano N, Malats N, Lopez-Botet M. Imprint of human cytomegalovirus infection on the NK cell receptor repertoire. Blood (2004) 104(12):3664-71. doi:10.1182/blood-2004-05-2058

56. Guma M, Budt M, Saez A, Brckalo T, Hengel H, Angulo A, et al. Expansion of CD94/NKG2C+ NK cells in response to human cytomegalovirus-infected fibroblasts. Blood (2006) 107(9):3624-31. doi:10.1182/blood-2005-09-3682

57. Paust S, Gill HS, Wang BZ, Flynn MP, Moseman EA, Senman B, et al. Critical role for the chemokine receptor CXCR6 in NK cell-mediated antigen-specific memory of haptens and viruses. Nat Immunol (2010) 11(12):1127-35. doi:10.1038/ni.1953

58. Sun JC, Beilke JN, Lanier LL. Adaptive immune features of natural killer cells. Nature (2009) 457(7229):557-61. doi:10.1038/nature07665

59. Netea MG, Joosten LA, Latz E, Mills KH, Natoli G, Stunnenberg HG, et al. Trained immunity: a program of innate immune memory in health and disease. Science (2016) 352(6284):aaf1098. doi:10.1126/science.aaf1098

60. Della Chiesa M, Sivori S, Carlomagno S, Moretta L, Moretta A. Activating KIRs and NKG2C in viral infections: toward NK cell memory? Front Immunol (2015) 6:573. doi:10.3389/fimmu.2015.00573

61. Prefumo F, Canini S, Casagrande V, Pastorino D, Venturini PL, De Biasio P. Correlation between first-trimester uterine artery Doppler indices and maternal serum free beta-human chorionic gonadotropin and pregnancy-associated plasma protein A. Fertil Steril (2006) 86(4):977-80. doi:10.1016/j.fertnstert.2006.01.063

62. Kozuki N, Lee AC, Silveira MF, Sania A, Vogel JP, Adair L, et al. The associations of parity and maternal age with small-for-gestational-age, preterm, and neonatal and infant mortality: a meta-analysis. BMC Public Health (2013) 13(Suppl 3):S2. doi:10.1186/1471-2458-13-S3-S2

63. Gamliel M, Goldman-Wohl D, Isaacson B, Gur C, Stein N, Yamin R, et al. Trained memory of human uterine NK cells enhances their function in subsequent pregnancies. Immunity (2018) 48(5):951-62e5. doi:10.1016/j. immuni.2018.03.030

64. Robertson SA. Immune regulation of conception and embryo implantation-all about quality control? J Reprod Immunol (2010) 85(1):51-7. doi:10.1016/j. jri.2010.01.008

65. Sonnenberg GF, Artis D. Innate lymphoid cells in the initiation, regulation and resolution of inflammation. Nat Med (2015) 21(7):698-708. doi:10.1038/ nm. 3892

66. Amsalem H, Kwan M, Hazan A, Zhang J, Jones RL, Whittle W, et al. Identification of a novel neutrophil population: proangiogenic granulocytes in second-trimester human decidua. J Immunol (2014) 193(6):3070-9. doi:10.4049/jimmunol.1303117

67. Croxatto D, Micheletti A, Montaldo E, Orecchia P, Loiacono F, Canegallo F, et al. Group 3 innate lymphoid cells regulate neutrophil migration and function in human decidua. Mucosal Immunol (2016) 9(6):1372-83. doi:10.1038/ mi.2016.10

68. Magri G, Miyajima M, Bascones S, Mortha A, Puga I, Cassis L, et al. Innate lymphoid cells integrate stromal and immunological signals to enhance antibody production by splenic marginal zone B cells. Nat Immunol (2014) 15(4):354-64. doi:10.1038/ni.2830

69. Jessmon P, Leach RE, Armant DR. Diverse functions of HBEGF during pregnancy. Mol Reprod Dev (2009) 76(12):1116-27. doi:10.1002/mrd.21066

70. Vinante F, Marchi M, Rigo A, Scapini P, Pizzolo G, Cassatella MA. Granulocytemacrophage colony-stimulating factor induces expression of heparin-binding epidermal growth factor-like growth factor/diphtheria toxin receptor and sensitivity to diphtheria toxin in human neutrophils. Blood (1999) 94(9):3169-77.

71. Costantini C, Cassatella MA. The defensive alliance between neutrophils and NK cells as a novel arm of innate immunity. J Leukoc Biol (2011) 89(2):221-33. doi:10.1189/jlb.0510250

72. Costantini C, Micheletti A, Calzetti F, Perbellini O, Pizzolo G, Cassatella MA. Neutrophil activation and survival are modulated by interaction with NK cells. Int Immunol (2010) 22(10):827-38. doi:10.1093/intimm/dxq434

73. Scapini P, Cassatella MA. Social networking of human neutrophils within the immune system. Blood (2014) 124(5):710-9. doi:10.1182/ blood-2014-03-453217

74. Thoren FB, Riise RE, Ousback J, Della Chiesa M, Alsterholm M, Marcenaro E, et al. Human NK Cells induce neutrophil apoptosis via an NKp46- and Fas-dependent mechanism. J Immunol (2012) 188(4):1668-74. doi:10.4049/ jimmunol.1102002

75. Kieckbusch J, Gaynor LM, Moffett A, Colucci F. MHC-dependent inhibition of uterine NK cells impedes fetal growth and decidual vascular remodelling. Nat Commun (2014) 5:3359. doi:10.1038/ncomms4359

76. Kopcow HD, Allan DS, Chen X, Rybalov B, Andzelm MM, Ge B, et al. Human decidual NK cells form immature activating synapses and are not cytotoxic. Proc Natl Acad Sci U S A (2005) 102(43):15563-8. doi:10.1073/ pnas.0507835102

77. Inada K, Shima T, Nakashima A, Aoki K, Ito M, Saito S. Characterization of regulatory T cells in decidua of miscarriage cases with abnormal or normal fetal chromosomal content. J Reprod Immunol (2013) 97(1):104-11. doi:10.1016/j.jri.2012.12.001

78. Tilburgs T, Roelen DL, van der Mast BJ, de Groot-Swings GM, Kleijburg C, Scherjon $\mathrm{SA}$, et al. Evidence for a selective migration of fetus-specific CD4+CD25bright regulatory $\mathrm{T}$ cells from the peripheral blood to the decidua in human pregnancy. J Immunol (2008) 180(8):5737-45. doi:10.4049/jimmunol.180.8.5737

79. Kammerer U, Eggert AO, Kapp M, McLellan AD, Geijtenbeek TB, Dietl J, et al. Unique appearance of proliferating antigen-presenting cells expressing DC-SIGN (CD209) in the decidua of early human pregnancy. Am J Pathol (2003) 162(3):887-96. doi:10.1016/S0002-9440(10)63884-9

80. Gustafsson C, Mjosberg J, Matussek A, Geffers R, Matthiesen L, Berg G, et al. Gene expression profiling of human decidual macrophages: evidence for 
immunosuppressive phenotype. PLoS One (2008) 3(4):e2078. doi:10.1371/journal. pone. 0002078

81. Vacca P, Cantoni C, Vitale M, Prato C, Canegallo F, Fenoglio D, et al. Crosstalk between decidual NK and CD14+ myelomonocytic cells results in induction of Tregs and immunosuppression. Proc Natl Acad Sci U S A (2010) 107(26):11918-23. doi:10.1073/pnas.1001749107

82. Vacca P, Montaldo E, Vitale C, Croxatto D, Moretta L, Mingari MC. MSC and innate immune cell interactions: a lesson from human decidua. Immunol Lett (2015) 168(2):170-4. doi:10.1016/j.imlet.2015.05.006

83. Erkers T, Nava S, Yosef J, Ringden O, Kaipe H. Decidual stromal cells promote regulatory $\mathrm{T}$ cells and suppress alloreactivity in a cell contact-dependent manner. Stem Cells Dev (2013) 22(19):2596-605. doi:10.1089/ scd.2013.0079

84. He YY, He XJ, Guo PF, Du MR, Shao J, Li MQ, et al. The decidual stromal cells-secreted CCL2 induces and maintains decidual leukocytes into Th2 bias in human early pregnancy. Clin Immunol (2012) 145(2):161-73. doi:10.1016/j. clim.2012.07.017

Conflict of Interest Statement: The authors declare that the research was conducted in the absence of any commercial or financial relationships that could be construed as a potential conflict of interest.

Copyright (c) 2018 Vacca, Vitale, Munari, Cassatella, Mingari and Moretta. This is an open-access article distributed under the terms of the Creative Commons Attribution License (CC BY). The use, distribution or reproduction in other forums is permitted, provided the original author(s) and the copyright owner(s) are credited and that the original publication in this journal is cited, in accordance with accepted academic practice. No use, distribution or reproduction is permitted which does not comply with these terms. 